\title{
Republished: Severe acute ocular hypertension following pulsed methylprednisolone for juvenile idiopathic arthritis
}

\author{
Andrew Beverstock, ${ }^{1}$ Alison Kelly ${ }^{2}$ \\ 'Department of Paediatric Orthopaedics, Bristol Royal Hospital for Children, Bristol, UK \\ ${ }^{2}$ Department of Paediatric Rheumatology, Bristol Royal Hospital for Children, Bristol, UK
}

Correspondence to: andrew.beverstockquhbristol.nhs.uk

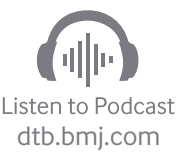

Republished from: Beverstock A, Kelly A, Severe acute ocular hypertension following pulsed methylprednisolone for juvenile idiopathic arthritis. BMJ Case Rep 2019;12:e229803. doi:10.1136/bcr-2019-229803

In conjunction with BMJ Case Reports, DTB will feature occasional drug-related cases that are likely to be of interest to readers. These will include cases that involve recently marketed drugs for which there is limited knowledge of adverse effects and cases that highlight unusual reactions to drugs that have been marketed for several years.

\section{Summary}

We report the case of a 6-year-old girl with juvenile idiopathic arthritis and anterior uveitis who was treated with two doses of intravenous methylprednisolone for acute arthritis. She developed severe ocular hypertension (intraocular pressures (IOPs) of $54 \mathrm{~mm} \mathrm{Hg}$ in the right eye and $61 \mathrm{~mm} \mathrm{Hg}$ in the left eye) requiring inpatient therapy with intravenous acetazolamide. The normal range of values for IOP is 12-22 mm Hg. This severe case of acute intraocular hypertension due to systemic steroids highlights the need to consider monitoring of IOPs for children on high-dose topical and systemic steroids with risk factors for raised IOP.

\section{Background}

Ocular hypertension is a well-recognised side-effect of topical and systemic corticosteroid therapy, but the majority of patients have a mild rise in intraocular pressure (IOP) of less than $20 \mathrm{~mm} \mathrm{Hg}$ which after withdrawal of steroids without the need for any additional treatment. ${ }^{1}$ The effect is more common with topical corticosteroid therapy.

This case is significant due to the rapid onset of the ocular hypertension and the severity of the rise. No report of such significantly elevated pressures after pulsed intravenous steroid therapy in such a young patient has been published. The case highlights the need to consider monitoring of IOPs following pulsed systemic steroids: in this case, the ocular hypertension was detected incidentally.

\section{Case presentation}

This patient was diagnosed with oligoarticular juvenile idiopathic arthritis (JIA) at age 3 following a 1-year history of left knee stiffness. Her JIA predominantly affected her left knee, left ankle and cervical spine. She was treated initially with intravenous methylprednisolone in 2012 to achieve remission before commencing maintenance methotrexate. She was screened on a six monthly basis for uveitis over the next 2 years and had no evidence of uveitis in this time. IOPs were not routinely measured.

She was diagnosed with bilateral anterior uveitis on the 2015 on routine screening and was commenced on Pred Forte (prednisolone acetate 1\% weight/volume) drops six times daily to both eyes. IOPs were not recorded due to patient distress at the time of examination. The following week, she was treated with $1000 \mathrm{mg}$ intravenous methylprednisolone as a day case for a flare-up of her neck symptoms of JIA, and she was due to return the following day for a second dose. On the day her second dose was due, her mother found her to be sleepier than usual, but no visual symptoms were reported.

She had a follow-up with the ophthalmologists arranged on the same day prior to attending the hospital for her second steroid intravenous infusion. Routine tonometry was performed using iCare tonometry at this appointment. This showed significant elevation of her IOPs, with a pressure of $53.6 \mathrm{~mm} \mathrm{Hg}$ in the right eye and $61.2 \mathrm{~mm} \mathrm{Hg}$ in the left eye. These measurements were repeatable. Ocular examination revealed mild anterior chamber activity with $0.5+$ cells in both anterior chambers.

The follow-up had been arranged prior to the administration of her systemic steroids, and thus her ocular hypertension contributed to by the intravenous methylprednisolone was picked up almost incidentally rather than through specific screening.

\section{Treatment}

Due to her extremely high IOPs, the patient was admitted for intravenous acetazolamide and topical antihypertensive therapy. After a single dose of intravenous acetazolamide her pressures improved to $25 \mathrm{~mm} \mathrm{Hg}$ in the right eye and $35 \mathrm{~mm} \mathrm{Hg}$ in the left eye. After two further doses her pressures were $17 \mathrm{~mm} \mathrm{Hg}$ bilaterally, within the normal range. She was commenced on 
topical timolol, latanoprost and brinzolamide, and 7 days later, her pressures were $14 \mathrm{~mm} \mathrm{Hg}$ bilaterally.

Systemic steroids were discontinued, and she was commenced on adalimumab for long-term control of her arthritis and uveitis.

\section{Outcome and follow-up}

Her pressures remained low at $12 \mathrm{~mm} \mathrm{Hg}$ bilaterally on long-term follow-up. Topical therapy was discontinued in January 2016 and her IOPs remained normal. Her uveitis was well controlled on adalimumab with no side effects. She had close follow-up for the next 3 years, and her IOPs remain normal.

She received an intra-articular injection of $30 \mathrm{mg}$ triamcinolone acetonide but had normal IOPs before and 48 hours after the procedure.

\section{Discussion}

Mild intraocular hypertension is a well-described side effect of both topical and systemic corticosteroid therapy: mild rises in IOP occur in up to $60 \%$ of patients, ${ }^{2}$ but significant rises are uncommon. Risk factors for raised IOP following steroid administration include a previous history of uveitis, ${ }^{2}$ comorbid connective tissue disease ${ }^{3}$ and younger age. ${ }^{4}$ Severe intraocular hypertension can be vision threatening but is frequently asymptomatic; therefore, early recognition and management is important.

Our case is noteworthy for several reasons: the severity of the ocular hypertension, the rapid speed of onset following the administration of intravenous steroids and due to its asymptomatic nature, being discovered almost incidentally. A previous published case described a patient with symptoms (headaches, eye pain, reduced visual acuity), ${ }^{5}$ while another described the onset following several months of therapy, ${ }^{6}$ but none described such markedly raised pressures in an asymptomatic patient.

Additionally this case highlights that significant intraocular hypertension can present very differently in children. Adults with such significant rises in IOP typically present with headaches and visual disturbance. ${ }^{7}$ The patient in this case was only fatigued, and had neither of these classical symptoms. Thus it is important to consider the diagnosis in children even in the absence of classical symptoms.

\section{Patient's perspective}

(Written by the patient's mother) This was the hardest day that we have had to deal with regarding our daughter's condition. To be told that we may have to go to London for her to have an operation on her eyes was very hard to digest. My little girl having medication that was supposed to help her that could make her go blind was so scary. If we had not have gone into the eye hospital for a routine check-up that morning then I really don't want to think where we would be now. The adult doctor that was called didn't believe that her pressures were up so high: he came in from home to check them himself. He said that if the pressure was up this high in an adult that they would be presenting very different to how our child was presenting. All she wanted to do was go to sleep and not open her eyes. She was very lethargic and had no energy to do anything. We want to make doctors aware that this can happen and to prevent some other family from going through what we went through.
This patient developed severe ocular hypertension due to a combination of her topical prednisolone drops and pulsed intravenous methylprednisolone therapy. It is not possible to determine the precise contribution of each to her ocular hypertension, but it is likely that the severity of her ocular hypertension was related to the combination of both routes of administration. She developed this condition within 3 weeks of commencing topical steroid therapy. Had she not been followed-up for her uveitis the high pressure may have been missed. Routine measurement of IOP for patients receiving topical and intravenous steroid therapy with risk factors may be advisable to allow early detection and management of this condition.

Learning points

- Steroid-induced ocular hypertension can occur in patients with juvenile idiopathic arthritis treated with systemic steroids.

- It is usually asymptomatic and can be easily missed without screening. This puts patients at risk of sight-threatening glaucomatous optic neuropathy.

- Consider screening for ocular hypertension following pulsed intravenous methylprednisolone therapy, especially in patients using topical ocular steroids.

Contributors $A B$ wrote initial draft. AK amended the draft and approved the final version.

Funding The authors have not declared a specific grant for this research from any funding agency in the public, commercial or not-for-profit sectors.

Competing interests None declared.

Patient consent for publication Parental/guardian consent obtained.

Provenance and peer review Not commissioned; externally peer reviewed.

Open access This is an open access article distributed in accordance with the Creative Commons Attribution Non Commercial (CC BY-NC 4.0) license, which permits others to distribute, remix, adapt, build upon this work noncommercially, and license their derivative works on different terms, provided the original work is properly cited and the use is non-commercial. See: http://creativecommons.org/licenses/by-nc/4.0/

(c) Author(s) (or their employer(s)) 2019. No commercial re-use. See rights and permissions. Published by BMJ.

\section{References}

1 Chy L, Dorothy SP, Jonathan CH, et al. Corticosteroid-induced glaucoma in children. Hong Kong J Ophthalmol 2014;18:14-19.

2 Kramar M, Vu L, Whitson JT, et al. The effect of intravitreal triamcinolone on intraocular pressure. Curr Med Res Opin 2007;23:1253-8.

3 Phulke S, Kaushik S, Kaur S, et al. Steroid-induced glaucoma: an avoidable irreversible blindness. J Curr Glaucoma Pract 2017;11:67-72.

4 Jonas JB, Degenring RF, Kreissig I, et al. Intraocular pressure elevation after intravitreal triamcinolone acetonide injection. Ophthalmology 2005;112:593-8.

5 Fitzgerald LA, Dudley J, Inward C, et al. Under pressure: an ocular complication of oral corticosteroid therapy. BMJ Case Rep 2012;2012:bcr2012006955.

6 Sousa DC, Leal I, Abegão Pinto L. Steroid-induced protracted severe ocular hypertension in a 14-year-old girl. BMJ Case Rep 2018;38:bcr-2018-225244.

7 Kohndkaryan A, Francis B. Angle-Closure glaucoma. BMJ Best Practice 2018.

DOI: 10.1136/dtb.2019.229803rep 